\title{
Calcipotriol/betamethasone dipropionate in the treatment of psoriasis vulgaris
}

\author{
Efstratios Vakirlis \\ Athanasios Kastanis \\ Demetrios loannides \\ A' Department of Dermatology, \\ Aristotle University of Thessaloniki, \\ Greece
}

\begin{abstract}
Psoriasis is one of the most common skin diseases. The mainstay of treatment for the vast majority of patients is topical therapy. A rising first-line treatment modality for psoriasis vulgaris is the two-compound ointment containing calcipotriol $50 \mu \mathrm{g} / \mathrm{g}$ plus betamethasone dipropionate $0.5 \mathrm{mg} / \mathrm{g}$ (Dovobet ${ }^{\circledR}$, Daivobet ${ }^{\circledR}$, Taclonex $^{\circledR}$ ), which combines a vitamin D analog and a corticosteroid. This innovative formulation preserves the activity and bioavailability of the two components and many clinical studies have demonstrated that it has a greater efficacy, tolerability, and a rapid onset of action compared with its individual ingredients or tacalcitol.
\end{abstract}

Keywords: psoriasis, calcipotriol/betamethasone dipropionate, dovobet, daivobet, taclonex

\section{Introduction}

Psoriasis is a chronic inflammatory skin disease with increased epidermal proliferation. Psoriasis vulgaris, the most common form of psoriasis, is usually characterized by well-circumscribed, red, raised, scaly plagues. Lesions usually occur symmetrically, affecting the knees, elbows, buttocks, scalp, extremities and areas subjected to trauma (Gottlieb 1998). The prevalence of psoriasis is generally estimated at between $0.5 \%-4.6 \%$ of the global population with rates varying among countries (Plunkett and Marks 1998; Koo 1999; Christophers 2001; Lebwohl 2003; Getland et al 2005). By combining age of onset and human leukocyte antigen pattern, two subtypes of psoriasis have been described: Type I with early onset ( $<30$ years of age) and familial inheritance; Type II psoriasis is usually a milder disease starting at age 55-60 years with no genetic predisposition (Swanbeck et al 1995).

Psoriasis has a significant impact on patient quality of life. The social and psychological impact is considerable. Psoriasis is not considered a life-threatening disease, but it is well established that those patients may experience a range of psychosocial difficulties, including elevated levels of anxiety, depression, and worry (Richards and Fortune 2006).

The histopathology is characterized by increased rate of epidermal proliferation with impaired differentiation of keratinocytes. Dermal blood vessels are dilated and there is infiltration of the skin with immunologically active cells (Bos 1988).

The etiopathogenesis of psoriasis is still not fully understood and involves a complex interaction of genetic and environmental factors. Psoriasis was originally thought to be a keratinisation disorder, but now substantial evidence indicates that different components of the innate- and acquired-immunity ( $\mathrm{T}$ cells, dendritic cells, and inflammatory cytokines) are critically involved in initiating and maintaining the inflammatory response (Tagami and Alba 1997; Jullien 2006).

Topical therapy is the mainstay of treatment for mild to moderate psoriasis and often the initial treatment for severe psoriasis (Ashcroft et al 2000). About 80\% of patients with psoriasis are treated topically (Peeters et al 2005). Patients treated with 
phototherapy or systemic agents, including biological agents, can also be managed with topical agents as adjunctive therapy (Guenther et al 2004).

Topical corticosteroids and vitamin $\mathrm{D}_{3}$ analogue are the treatment of choice (van de Karkhof and Vissers 2003). Combination therapy is known to be superior to monotherapy and is commonly used. By combining medications with a different mechanism of action and safety profile, efficacy can be enhanced and/or safety improved. A calcipotriol/ betamethasone dipropionate two-compound ointment (Dovobet $^{\circledR}$, Daivobet ${ }^{\circledR}$, Taclonex ${ }^{\circledR}$, LEO Pharma A/S Ballerup, Denmark) has been shown to be safe and effective in the treatment of psoriasis vulgaris.

\section{Chemical properties, pharmacodynamics, and pharmacokinetics of calcipotriol/betamethasone dipropionate}

Calcipotriol (Daivonex ${ }^{\circledR}$, Dovonex ${ }^{\circledR}$ ), a synthetic analog of 1,25-dixydroxyvitamin $\mathrm{D}_{3}$, binds to the vitamin $\mathrm{D}$ receptor and act as a heterodimer with the retinoid X receptor (RXR) (Bury et al 2001). Vitamin D receptors are present on keratinocytes and lymphocytes. The epidermal hyperproliferation, abnormal keratinization, and angiogenesis seen in psoriasis are normalized with vitamin D analogs; apoptosis is induced in inflammatory cells and there is a switch from Th1 cytokines to Th2 cytokines (van de Kerkhof 1995, 1998; Barna et al 1997). To be more specific, calcipotriol can modulate the inflammatory process in psoriasis by decreasing the levels of interleukin-1 (IL-1) (Muller et al 1988) and IL-6 (Muller et al 1991) and by reducing the CD45RO and $\mathrm{C}^{+} \mathrm{T}$ cells. Morover, it increases the levels of transforming growth factor- $\beta 1$ (TGF- $\beta 1$ ) and $-\beta 2$, which inhibit the epithelial cell growth (Koli and Keski-Oja 1993). Calcipotriol is sensitive to oxidizing agents and acidic residues; it reacts with alcohols, and easily undergoes epimerisation processes (Charakida et al 2006). Twice-daily calcipotriol has an excellent safety profile (Cullen 1996) and is more efficacious than short-contact anthralin (Berth-Jones et al 1992), tar (Tham et al 1994), fluocinonide ointment (Bruce et al 1994) and is at least as efficacious as betamethasone 17 -valerate $0.1 \%$ ointment (Kragballe et al 1991; Cunliffe et al 1992). Despite its sideeffect of local irritation, calcipotriol is not associated with the cutaneous atrophy of topical corticosteroids or messiness of tar and anthralin.

Betamethasone dipropionate is a class III potency, synthetic, fluorinated topical steroid (World Health
Organization classification). Betamethasone binds to cytoplasmic glucocorticoid receptors and then is rapidly translocated to the nucleus where it stimulates or inhibits the genes regulating inflammation (Wissink et al 1998). Corticosteroids improve several markers of inflammation (infiltrate, erythema, edema, and hyperproliferation) in psoriasis vulgaris without affecting terminal differentiation (Fenlon and Plosker 2004). They also inhibit production of cytokines (IL-1, IL-6, IL-8, tumor necrosis factor- $\alpha$, interferon- $\gamma$ ), reduce mediators of inflammation (prostaglandins, leukotrienes, nitric oxide), decrease the abnormal CD4:CD8 ratio and the number and activity of Langerhans' cells (Beato 1989; De Jong et al 1995; Vissers et al 2004).

Corticosteroids are stable under acidic conditions, but sensitive to alkaline residues and oxidizing agents. If water is present in the formulation, calcipotriol requires a relatively high $\mathrm{pH}(>8)$ for maximum stability, whereas betamethasone dipropionate requires $\mathrm{pH}$-values in the range of 4-6 (Simonsen et al 2004). Calcipotriol and topical steroids are difficult to mix in the same single formulation because they inactivate each other.

In their study, Simonsen and colleagues (2004) demonstrated that it is possible to combine the two otherwise incompatible drug substances in a formulation by careful selection of the vehicle components. This new two-

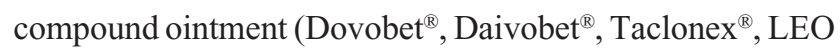
Pharma A/S Ballerup, Denmark) is a combination of calcipotriol $50 \mu \mathrm{g} / \mathrm{g}$ and betamethasone dipropionate $0.5 \mathrm{mg} / \mathrm{g}$ in a single vehicle (5\% polyoxypropylene-15-stearyl ether) achieving optimal delivery of both drugs in an active state into the skin (Simonsen et al 2004), without affecting each other's absorption (Hansen 2001; Guenther 2005) and it is stable and active for more than 2 years at room temperature (Traulsen 2004).

The combination of calcipotriol with a corticosteroid improves efficacy and decreases skin irritation. Two studies showed that the administration of the combination of calcipotriol and betamethasone dipropionate for a 4-week period improved keratinocyte proliferation, differentiation (Van Rossum et al 2001; Vissers et al 2004), and inflammatory characteristics (Van Rossum et al 2001). Also this new two-compound ointment induces a steroid-sparing effect in long-term treatments and thereby reduces the risk of skin atrophy and skin thickness (Traulsen et al 2003), stretch marks, telangiectasia, rebound phenomenon, and tachyphylaxis. Tachyphylaxis is a clinical concern, but it was not reported in the clinical studies. The intermittent use of corticosteroid or the use of a potent antipsoriatic agent (calcipotriol) may 
possibly be attributable to prevention or minimization of tachyphylaxis (Singh et al 2000). A steroid-sparing effect and the improvement of patient compliance are expected with a once-daily treatment regimen and the faster onset of action. Last, but not least, the systemic absorption of calcipotriol and betamethasone dipropionate from the combination product through normal skin is less than $1 \%$.

\section{Clinical efficacy}

To date, six large phase III international, multicenter, prospective, randomized, blinded, clinical studies with the two-compound ointment have been performed, including more than 6000 patients with psoriasis vulgaris (Douglas et al 2002; Guenther et al 2002; Kaufman et al 2002; Papp et al 2003; Kragballe et al 2004; Ortonne et al 2004). These studies have shown that after 4 weeks of treatment, the mean reduction of Psoriasis Area and Severity Index (PASI) ranged from $65 \%-74.4 \%$ with the two-compound ointment applied once or twice daily (Kragballe and van de Kerkhof 2006), while calcipotriol, tacalcitol, or betamethasone dipropionate alone produced a mean reduction of PASI ranging from $46 \%$ to $59 \%, 33.3 \%$, and from $57 \%$ to $63 \%$, respectively. In a study where the two-compound ointment was applied once daily for 8 weeks, the maximum treatment effect was noted after 5 weeks and was maintained throughout the 8-week treatment period (Kragballe et al 2004).

Patient demographics were similar in all six studies:

- Mean age: 48 years

- Male (\%): 53.8-69.6 (mean 60\%)

- Baseline PASI: 9.7-10.9 (mean 10)

- Duration of psoriasis (years): 18.3-20.2 (mean 19 years)

The six studies (Table 1) were designed to compare uses of the two-compound ointments (Kragballe and van de Kerkhof 2006):

- Study 1: the two-compound ointment was applied twice daily, with each of the active ingredients applied twice daily alone in the new vehicle (Papp et al 2003)

- Study 2: the two-compound ointment was applied twice daily, with each of the active ingredients applied twice daily in their marketed ointment formulation (Douglas et al 2002)

- Study 3: the two-compound ointment was applied once or twice daily, with calcipotriol ointment applied twice daily (Guenther et al 2002)

- Study 4: the two-compound ointment was applied once daily, with each of the active ingredients applied once daily alone in the new vehicle (Kaufmann et al 2002)
Table I Comparision of studies on the treatment of psoriasis vulgaris with two-compound ointment

\begin{tabular}{|c|c|c|}
\hline Study I & Papp et al 2003 & $\begin{array}{l}\text { Two-compound ointment applied } \\
\text { twice daily, with each of the active } \\
\text { ingredients applied twice daily alone } \\
\text { in the new vehicle }\end{array}$ \\
\hline Study 2 & Douglas et al 2002 & $\begin{array}{l}\text { Two-compound ointment applied } \\
\text { twice daily, with each of the active } \\
\text { ingredients applied twice daily with } \\
\text { their marketed ointment formulation }\end{array}$ \\
\hline Study 3 & Guenther et al 2002 & $\begin{array}{l}\text { Two-compound ointment applied } \\
\text { once or twice daily, with calcipotriol } \\
\text { ointment applied twice daily }\end{array}$ \\
\hline Study 4 & Kaufmann et al 2002 & $\begin{array}{l}\text { Two-compound ointment applied } \\
\text { once daily, with each of the active } \\
\text { ingredients applied once daily alone in } \\
\text { the new vehicle }\end{array}$ \\
\hline Study 5 & Kragballe et al 2004 & $\begin{array}{l}\text { I.Two compound ointment applied } \\
\text { once daily for } 8 \text { weeks followed by } \\
\text { calcipotriol once daily for } 4 \text { weeks } \\
\text { 2. Daily use for } 4 \text { weeks followed by } \\
8 \text { weeks of treatment with calcipot- } \\
\text { riol once daily on weekdays and the } \\
\text { two-compound product once daily at } \\
\text { weekends and } \\
\text { 3. Calcipotriol ointment twice daily } \\
\text { for } 12 \text { weeks }\end{array}$ \\
\hline Study 6 & Ortonne et al 2004 & $\begin{array}{l}\text { I.The two-compound ointment } \\
\text { applied once daily, with } \\
\text { 2. Tacalcitol ointment applied once } \\
\text { daily }\end{array}$ \\
\hline
\end{tabular}

- Study 5: the two-compound ointment was applied once daily for 8 weeks followed by calcipotriol once daily for 4 weeks, with a) the two compound ointment applied once daily for 4 weeks followed by 8 weeks of treatment with calcipotriol once daily on weekdays and the two-compound product once daily at weekends and b) calcipotriol ointment twice daily for 12 weeks (Kragballe et al 2004)

- Study 6: the two-compound ointment was applied once daily, with tacalcitol ointment applied once daily (Ortonne et al 2004)

It is clearly demonstrated by these studies that the twocompound ointment of calcipotriol/betamethasone dipropionate applied once daily is more effective than either agent alone or tacalcitol; it has a more rapid onset of action and this effect is sustained. These advantages are not affected by age (Parslew and Traulsen 2005), sex, or baseline disease severity (van de Kerkhof et al 2005; Anstey and Kragballe 2006). Anstey and Kragballe (2006) conducted a very interesting study. 
Results from these six phase III studies for the two-compound ointment were pooled and the PASI 50 and PASI 75 response rates were calculated for patients with severe $(\mathrm{PASI} \geq 17)$ or less severe psoriasis $(\mathrm{PASI}<17)$ at baseline. Results from phase III studies using the biological agents efalizumab, etanercept, or alefacept were also pooled. In patients with severe psoriasis, the PASI 50 response rate was $88.8 \%$ after 4 weeks of treatment with the two-compound ointment, $69.2 \%$ with betamethasone dipropionate, $53.8 \%$ with calcipotriol, and $30 \%$ with ointment vehicle. The PASI 75 response rate in patients with severe psoriasis was $54.1 \%$ treated with the two-compound ointment for 4 weeks, $32.7 \%$ of patients treated with betamethasone dipropionate, and $20 \%$ of calcipotriol-treated patients. The number of patients achieving PASI 50 and PASI 75 after 12 weeks of treatment with biologicals was $56 \%$ and $28 \%$ for alefacept, $59 \%$ and $27 \%$ for efalizumab, and $74 \%$ and $49 \%$ for etanercept, respectively. Indirect comparisons across studies should be interpreted with caution (Antsey and Kragballe 2006). Nevertheless, it is important to point out the efficacy and the rapid onset of action of a topical treatment in patients with severe disease. Further clinical trials comparing the effectiveness between biological and topical therapies for psoriasis must be conducted to determine the treatment of choice for severe psoriasis.

Another study from van de Kerkhof (2004) assessed the impact of treatment with the two-compound ointment on patient quality of life (QoL). A statistically significant positive effect on patient QoL was noted, which reflects the superior efficacy of calcipotriol/betamethasone dipropionate ointment and the advantage of once-daily application.

A randomized parallel-group clinical trial was designed to investigate the efficacy and safety of two maintenance regimens ( 8 weeks calcipotrol cream applied once daily or calcipotriol cream weekdays/two-compound ointment weekends) compared with vehicle, after 4 weeks' acute treatment of calcipotriol/betamethasone dipropionate (White et al 2006). The group of patients which used the two-compound ointment on weekends during the maintenance period had a greater reduction in PASI (58.4\%), than calcipotriol (44.5\%) and vehicle $(33.1 \%)$ at week 12 .

Finally, to investigate the long term safety (Kragballe et al 2006a) and efficacy (Kragballe et al 2006b) of the two-compound ointment, a randomized, double-blind, 52-week, study was performed. In this double-blind study, 634 patients were randomized with once-daily (when required) treatment with either: 52 weeks of two-compound product $(\mathrm{n}=212), 52$ weeks of alternating 4 -week periods of two-compound product and calcipotriol $(\mathrm{n}=213)$, or 4 weeks of two-compound product followed by 48 weeks of calcipotriol $(n=209)$. Disease severity at baseline was moderate in $69.1 \%$ of patients, severe in $27.9 \%$, and very severe in $3.0 \%$. The median duration of psoriasis was 17.0 years and the mean age of patients was 48.8 years. Although long-term safety was the primary objective of the study, efficacy results were also presented. At the end of this study, more patients treated with calcipotriol/betamethasone dipropionate for 52 weeks had "satisfactory" responses to treatment as determined by the Investigators' Global Assessment compared with patients who received alternating two-compound product and calcipotriol, or two-compound product for 4 weeks and calcipotriol for 48 weeks, although this difference was not significant $(\mathrm{p}=0.071)$ (Kragballe et al 2006b), as the study was not designed to determine efficacy (Kragballe et al 2006b). In the alternating group, the proportion of satisfactory responses after a calcipotriol/betamethasone dipropionate treatment period was always higher than that after a calcipotriol treatment period. These results provide evidence that the two-compound ointment used intermittently, as needed for 52 weeks, showed no sign of tachypylaxis and effectively controlled psoriasis (Kragballe et al 2006b).

\section{Safety and tolerability}

The two-compound ointment with calcipotriol/betamethasone dipropionate is safe and well-tolerated for the treatment of psoriasis vulgaris, as has been shown by the clinical trials mentioned above (Douglas et al 2002; Guenther et al 2002; Kaufmann et al 2002; Papp et al 2003; Kragballe et al 2004; Ortonne et al 2004). The most common adverse drug reactions were those related to irritation of the skin (lesional/perilesional, pruritus, burning, erythema) (Guenther et al 2002; Kaufmann et al 2002; Papp et al 2003) and appeared in $2.6 \%$ of once-daily calcipotriol/betamethasone dipropionate recipients or $4.9 \%-5.1 \%$ of twice daily calcipotriol/betamethasone dipropionate recipients. Skin atrophy was noted in one recipient of the two-compound ointment in each of the three trials.

The only serious, possibly drug-related, adverse event reported was facial edema in a patient with widespread, oozing, crusting psoriasis after 2 weeks' treatment with the two-compound ointment twice-daily, which was resolved after the discontinuation of the product (Douglas et al 2002).

The adverse events associated with long-term topical corticosteroid use in the 52-week safety study were recorded by the investigators and were adjudicated by an independent panel of 3 dermatologists who were blinded to the treatments 
(Kragballe et al 2006a). There were 10 patients (4.8\%) with 11 adjudicated corticosteroid-related adverse events in the two-compound ointment group, 6 patients $(2.8 \%)$ with 7 events in the alternating group, and 6 patients $(2.9 \%)$ with 6 such events in the two-compound ointment 4 weeks/calcipotriol 48 weeks group. Median time to onset of an adverse event was 13, 25, and 20 weeks, respectively.

There were no statistically significant differences between treatment groups. One of the major concerns of long-term topical corticosteroid use, the incidence of skin atrophy, was low in all groups:

- In the group that received the two-compound ointment for 4 weeks and then calcipotriol for 48 weeks, skin atrophy was observed in 2 patients, even though they received very little topical corticosteroid over the course of the study. Furthermore, in both cases, the skin atrophy was reported rather late during the clinical study, when the two patients were under calcipotriol treatment. Other adverse events were: adrenal insufficiency, which was observed toward the end of the treatment period (week 52) in 1 patient which was possibly unrelated to the use of the study treatment, cellulitis, hypertrichosis, and purpura (each in one patient)

- One case of skin atrophy was observed in the alternating two-compound ointment/calcipotriol regimen. Folliculitis, pustular rash, skin papilloma, strie (each in one patient), and furuncles (two patients) were also reported.

- Four cases of skin atrophy were noted in patients receiving the two-compound ointment for the entire period and after 10 to 33 weeks in the study. In 3 patients the atrophy resolved. Other adverse events were folliculitis (three patients), skin depigmentation (two patients), ecchymosis, and purpura (each in one patient).

No significant changes in serum calcium were reported in these clinical trials (Guenther 2005), systematic absorption is minimal (Guenther 2005), and the number of lesional/perilesional adverse drug reactions for patients $<60$ years of age and those $\geq 60$ years was similar (6.4\% vs $5.0 \%$ ) (Parslew and Traulsen 2005).

The better tolerability of the two-compound ointment is thought to be due to the anti-inflammatory effect of betamethasone. The corticosteroid in the two-compound ointment seems to minimize the adverse events (irritation) of calcipotriol.

\section{Dosage and administration}

Calcipotriol $50 \mu \mathrm{g} / \mathrm{g}$ plus betamethasone dipropionate 0.5 $\mathrm{mg} / \mathrm{g}$ ointment is indicated for the topical treatment of stable plaque psoriasis vulgaris in adults 18 years of age and above.
The recommended treatment period is 4 weeks. After this period, repeated treatment with the two-compound product can be initiated under medical supervision according to the new product label. It should be applied once daily on $\leq 30 \%$ of the body surface. The maximum dose should not exceed $15 \mathrm{~g} /$ day and $100 \mathrm{~g} /$ week. The two-compound product should not be applied to the face, axillae, groin, or thin skin areas (van de Kerkhof et al 2006) and is contraindicated 1) in those patients with a history of hypersensitivity to any of the components, 2) in patients with disorders of calcium metabolism, and 3) in patients with erythrodermic, exfoliative, and pustular psoriasis.

\section{Pharmacoeconomic analyses}

Calcipotriol/betamethasone dipropionate ointment applied once-daily is more effective and less costly than tacalcitol or calcipotriol for treating psoriasis (Fenton and Plosker 2004; Peeters et al 2005; Charakida et al 2006).

\section{Conclusion}

The two-compound ointment with calcipotriol $50 \mu \mathrm{g} / \mathrm{g}$ and betamethasone dipropionate $0.5 \mathrm{mg} / \mathrm{g}$ is a convenient, very effective, safe, and well tolerated therapy for psoriasis. The percentage of patients with a satisfactory response is higher with the two-compound ointment than with other topical treatments used in the past. Patients also are satisfied by the treatment, their clinical condition improves quickly, and significant results are seen in 1 week. This aids compliance. It is well known that lack of efficacy can have a negative effect on compliance as indicated by a recent finding that up to $40 \%$ of patients were intentionally noncompliant with their therapy because they believed the treatment took too long to have an effect (Peeters et al 2005). The two-compound ointment with its rapid onset of action and sustained efficacy can quickly clear resistant lesions such as those on the elbows, knees, and legs, thus motivating patients to maintain compliance with their therapy (Carroll et al 2004; Antsey and Kragballe 2006). Another issue that may enhance compliance is the simple once-daily application.

Treatment efficacy, due to the synergistic clinical effect of two widely used compounds, provides a strong improvement of patients' PASI irrespective of the severity of psoriasis. In clinical trials, patients with a mean baseline PASI of 9.5-10.9 experienced a mean $65.0 \%-74.4 \%$ PASI improvement within 4 weeks. In addition, in $6.1 \%-20.1 \%$ of patients, lesions cleared. Today the two-compound ointment is the most effective topical treatment for psoriasis vulgaris, which is currently available (Charakida et al 2006). Certainly there 


\section{TREATMENT RECOMMENDATION}

\section{Acute treatment:} DOVOBET OD
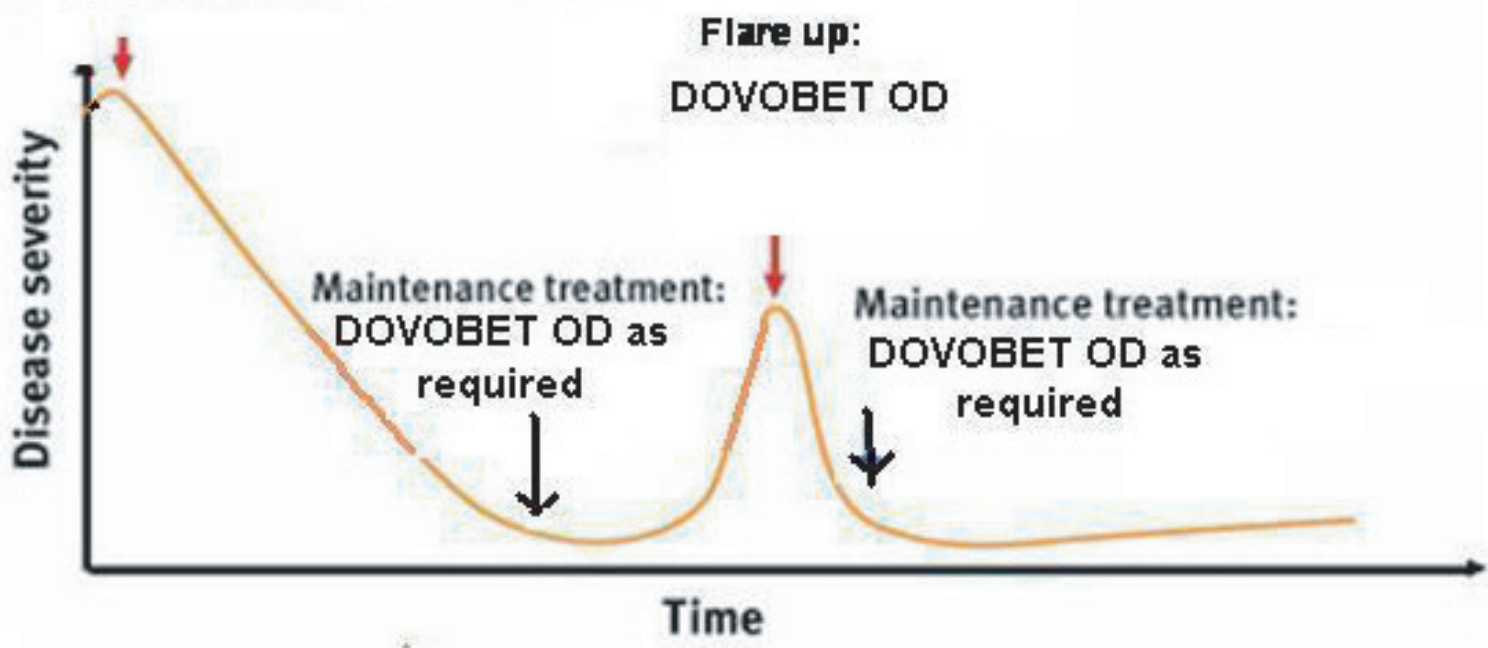

\section{OD:once daily}

Figure I Treatment recommendation.

Abbreviation: $\mathrm{OD}$, once daily.

are some patients who fail to respond to the treatment for a reason which remains unclear.

Recent studies provide good evidence that the twocompound ointment is safe and well-tolerated in repetitive use as required over a longer period of time for up to 52 weeks. Pooled safety data from 7 clinical studies proved that the twocompound ointment is safe, with side effects mainly involving local skin reactions of mild intensity (Papp and Melgaard 2007). The proportion of patients with adverse drug reactions was smaller with the two-compound ointment and there was no increase in corticosteroid-related adverse events.

The two-compound ointment with calcipotriol $50 \mu \mathrm{g} / \mathrm{g}$ and betamethasone dipropionate $0.5 \mathrm{mg} / \mathrm{g}$ should be seen as the first-line treatment of choice for psoriasis vulgaris amenable to topical treatment (Charakida et al 2006) and should be used acutely for 4-8 weeks to bring psoriasis under control. After this, control of the disease can be maintained either 1) with calcipotriol monotherapy on weekdays and two-compound ointment on weekends or three-times a week (Monday/Wednesday/Friday) (Guenther 2005) or 2) with the two-compound ointment once-daily as needed (Figure 1).
The latter treatment recommendation would possibly enhance patient adherence to treatment as it does not involve two different medications and provides an opportunity for individualized treatment regimen.

Psoriasis is a chronic disease and usually requires longterm treatment with optimal safety. Approximately $70 \%-80 \%$ of all patients with psoriasis can be managed adequately with use of topical therapy alone (Sterry et al 2004; Schön and Boehncke 2005). In conclusion, the two-compound ointment should be considered as the initial therapeutic approach for psoriasis vulgaris or as an adjunctive therapy in patients on systemic agents (acitretin, methotrexate, cyclosporine, biologics) or phototherapy (Rogers 2006).

\section{References}

Anstey AV, Kragballe K. 2006. Retrospective assessment of PASI 50 and PASI 75 attainment with a calcipotriol/betamethasone dipropionate ointment. Inter J Dermatol, 45:970-5.

Ashcroft DM, Li Wan Po A, Griffiths CE. 2000. Therapeutic strategies for psoriasis. J Clin Pharm Ther, 25:2-10.

Barna M, Bos JD, Kapsenberg ML, et al. 1997. Effect of calcitriol on the production of T-cell-derived cytokines in psoriasis. $\mathrm{Br} J$ Dermatol, $136: 536-41$. 
Beato M. 1989. Gene regulation by steroid hormones. Cell, 56:335-44 .

Berth-Jones J, Chu AC, Dodd WAH, et al. 1992. A multi-centre, parallelgroup comparison of calcipotriol ointment and short-contact dithranol therapy in chronic plaque psoriasis. Br J Dermatol, 127:266-71.

Bos JD. 1988. The pathomechanisms of psoriasis; the skin immune system and cyclosporine. Br J Dermatol, 118:141-55.

Bruce S, Epinette WW, Funicella T, et al. 1994. Comparative study of calcipotriol (MC 903) ointment and fluocinonide ointment in the treatment of psoriasis. J Am Acad Dermatol, 31:755-9.

Bury Y, Ruf D, Hansen CM, et al. 2001. Molecular evaluation of vitamin D3 receptor agonists designed for topical treatment of skin diseases. J Invest Dermatol, 116:785-92.

Carroll CL, Feldman SR, Camacho FT, et al. 2004. Adherence to topical therapy decreases during the course of an 8 -week psoriasis clinical trial: commonly used methods of measuring adherence to topical therapy overestimate actual use. J Am Acad Dermatol, 51:212-16.

Charakida A, Dadzie O, Teixeira F, et al. 2006. Calcipotriol/Betamethasone dipropionate for the treatment of psoriasis. Expert Opin Pharmacother, 7:597-606.

Christophers E. 2001. Psoriasis-epidemiology and clinical spectrum. Clin Exp Dermatol, 26:314-20.

Cullen SI. 1996. Long-term effectiveness and safety of topical calcipotriene for psoriasis. South Med J, 89:1053-6.

Cunliffe WJ, Berth-Jones J, Claudy A, et al. 1992. Comparative study of calcipotriol (MC 903) ointment and betamethasone 17-valerate ointment in patients with psoriasis vulgaris. $J$ Am Acad Dermatol, 26(5 Pt 1):736-43.

De Jong EM, Ferrier CM, de Zwart A, et al. 1995. Effects of topical treatment with budesonide on parameters for epidermal proliferation, keratinization and inflammation in psoriasis. J Dermatol Sci, 9:185-94.

Douglas WS, Poulin Y, Decroix J, et al. 2002. A new calcipotriol/ betamethasone formulation with rapid onset of action was superior to monotherapy with betamethasone dipropionate or calcipotriol in psoriasis vulgaris. Acta Derm Venereol, 82:31-5.

Fenton C, Plosker G. 2004. Calcipotriol/Betamethasone dipropionate: A review. Am J Clin Dermatol, 5:463-78.

Gelfand JM, Weinstein R, Porter SB, et al. 2005. Prevalence and treatment of psoriasis in the United Kingdom. Arch Dermatol, 141:1537-41.

Gottlieb AB. 1998. Psoriasis. Dis Manage Clin Outcomes, 1:195-202.

Guenther L, Cambazard F, van de Kerkhof PCM, et al. 2002. Efficacy and safety of a new combination of calcipotriol and betamethasone dipropionate (once or twice daily) compared to calcipotriol (twice daily) in the treatment of psoriasis vulgaris: a randomized, double-blind, vehicle-controlled clinical trial. Br J Dermatol, 147:316-23.

Guenther L, Langley RG, Shear NH, et al. 2004. Integrating biologic agents into management of moderate-to-severe psoriasis: a consensus of the Canadian psoriasis expert panel. J Cut Med Surg, 8:321-37.

Guenther LC. 2005. Calcipotriol/Betamethasone dipropionate: Daivobet/ Dovobet. Therapy, 2:343-48.

Hansen J. 2001. Mixing the unmixable. Verbal communication at the Leo Satellite Symposium. 10th Congress of the European Academy of Dermatology and Venereology, Oct 10-14, Munich, Germany.

Jullien D. 2006. Psoriasis physiopathology. J Eur Acad Dermatol Venereol, 20(suppl. 2):10-23.

Kaufmann R, Bibby AJ, Bissonnette R, et al. 2002. A new calcipotriol/betamethasone dipropionate formujlation (Daivobet ${ }^{\mathrm{TM}}$ ) is an effective once daily treatment for psoriasis vulgaris. Dermatology, 205:389-93.

Koli K, Keski-Oja J. 1993. Vitamin D3 and calcipotriol enhance the secretion of transforming growth factor -beta 1 and -beta 2 in cultured murine keratinocytes. Growth Factors, 8:153-63.

Koo JY. 1999. Current consensus and update on psoriasis therapy: a perspective from the U.S. J Dermatol, 26:723-33.

Kragballe K, Austad J, Barnes L, et al. 2006a. A 52-week randomized safety study of a calcipotriol/betamethasone dipropionate two-compound product $\left(\right.$ Dovobet $^{\mathbb{\mathbb { }}} /$ Daivobet $^{\mathbb{\mathbb { P }}} /$ Taclonex $^{\mathbb{\circledR}}$ ) in the treatment of psoriasis vulgaris. Br J Dermatol, 154:1155-60.
Kragballe K, Austad J, Barnes L, et al. 2006b. Efficacy results of a 52-week, randomized, double-blind, safety study of a calcipotriol/betamethasone dipropionate two-compound product (Dovobet ${ }^{\mathbb{1}} /$ Daivobet $^{\mathbb{\circledR}} /$ Taclonex $^{\circledR}$ ) in the treatment of psoriasis vulgaris. Dermatology, 213:319-26.

Kragballe K, Gjertsen B, de Hoop D, et al. 1991. Double-blind, right/left comparison of calcipotriol and betamethasone valerate in treatment of psoriasis vulgaris. Lancet, 337:193-6.

Kragballe K, Noerrelund KL, Lui H, et al. 2004. Efficacy of once-daily treatment regimens with calcipotriol/betamethasone dipropionate ointment and calcipotriol ointment in psoriasis vulgaris. $\mathrm{Br} J$ Dermatol, 150:1167-73.

Kragballe K, van de Kerkhof PC. 2006. Consistency of data in six phase III clinical studies of a two-compound product containing calcipotriol and betamethasone dipropionate ointment for the treatment of psoriasis. $J$ Eur Acad Dermatol Venereol, 20:39-44.

Lebwohl M. 2003. Psoriasis. Lancet, 361:1197-204.

Muller K, Diamant M, Bendtzen K. 1991. Inhibition of production and function of interleukin- 6 by 1, 25 -dixydroxyvitamin $\mathrm{D}_{3}$. Immunol Lett, 28:115-20.

Muller K, Svenson M, Bendtzen K. 1988. 1 alpha, 25 -Dixydroxyvitamin $\mathrm{D}_{3}$ and a novel vitamin D analogue MC 903 are potent inhibitors of human interleukin 1 in vivo. Immunol Lett, 17:361-5.

Ortonne JP, Kaufmann R, Lecha M, et al. 2004. Efficacy of treatment with calcipotriol/betamethasone dipropionate followed by calcipotriol alone compared with tacalcitol for the treatment of psoriasis vulgaris: a randomized, double-blind trial. Dermatology, 209:308-13.

Papp K, Melgaard A. 2007. Pooled safety data for a calcipotriene/betamethasone dipropionate two-compound product in the treatment of psoriasis vulgaris $J$ Am Acad Dermatol, 56(2, Suppl. 2):AB183.

Papp KA, Guenther L, Boyden B, et al. 2003. Early onset of action and efficacy of a combination of calcipotriene and betamethasone dipropionate in the treatment of psoriasis. J Am Acad Dermatol, 48:48-54.

Parslew R, Traulsen J. 2005. Efficacy and local safety of a calcipotriol/ betamethasone dipropionate ointment in elderly patients with psoriasis vulgaris. Eur J Dermatol, 15:37-9.

Peeters P, Ortonne JP, Sitbon R, et al. 2005. Cost-effectiveness of once-daily treatment with calcipotriol/betamethasone dipropionate followed by calcipotriol alone compared with tacalcitol in the treatment of Psoriasis vulgaris. Dermatology, 211:139-45.

Peeters P, Ortonne JP, Sitbon R, et al. 2005. Cost-effectiveness of once-daily treatment with calcipotriol/betamethasone dipropionate followed by calcipotriol alone compared with tacalcitol in the treatment of psoriasis vulgaris. Dermatology, 211:139-45.

Plunkett A, Marks R. 1998. A review of the epidemiology of psoriasis vulgaris in the community. Australas J Dermatol, 39:225-32.

Richards HL, Fortune DG. 2006. Psychological distress and adherence in patients with psoriasis. J Eur Acad Dermatol Venereol, 20(suppl 2):33-41.

Rogers C. 2006. Calcipotriol (Dovobet ${ }^{\mathbb{1}}$ ) ointment in combination with UVB therapy for psoriasis treatment. Dermatol Nurs, 18:258-61.

Schön MP, Boehncke WH. 2005. Psoriasis. N Engl J Med, 352:1899-912.

Simonsen L, Hoy G, Didriksen E, et al. 2004. Development of a new formulation combining calcipotriol and betamethasone dipropionate in an ointment vehicle. Drug Dev Ind Pharm, 30:1095-102.

Singh S, Reddy DCS, Pandey SS. 2000. Topical therapy for psoriasis with the use of augmented betamethasone and calcipotriene on alternate weeks. J Am Acad Dermatol, 43:61-7.

Sterry W, Barker J, Boehncke WH, et al. 2004. Biological therapies in the systemic management of psoriasis: International Consensus Conference. Br J Dermatol, 151(Suppl 69):3-17.

Swanbeck G, Inerot A, Martinsson T, et al. 1995. Age at onset and different types of psoriasis. Br J Dermatol, 133:768-73.

Tagami H, Aiba S. 1997. Psoriasis. In: Bos JD (ed). Skin Immune System (SIS). 2nd ed. Boca Raton, New York: CRC Press LLC, pp 523-530.

Tham SN, Lun KC, Cheong WK. 1994. A comparative study of calcipotriene ointment and tar in chronic plaque psoriasis. $\mathrm{Br} J$ Dermatol, 131:673-7. 
Traulsen J, Hughes-Formella BJ. 2003. The atrophogenic potential and dermal tolerance of calcipotriene/betamethasone dipropionate oinment compared with betamethasone dipropionate ointment. Dermatology, 207:166-72.

Traulsen J. 2004. Bioavailability of betamethasone dipropionate when combined with calcipotriol. Int J Dermatol, 43:611-17.

van de Kerkhof PC, Vissers WH. 2003. The topical treatment of psoriasis. Skin Pharmacol Appl Skin Physiol, 16:69-83.

van de Kerkhof PC, Wasel N, Kragballe K, et al. 2005. A two compound product containing calcipotriol and betamethasone dipropionate provides rapid, effective treatment of psoriasis vulgaris regardless of baseline disease severity. Dermatology, 210:294-9.

van de Kerkhof PC, Kragballe K, Austad J, et al. 2006. Psoriasis: severity assessment in clinical practice. Conclusions from workshop discussions and a prospective multicentre survey of psoriasis severity. Eur $J$ Dermatol, 16:167-71.

van de Kerkhof PC. 1995. Biological activity of vitamin D analogues in the skin, with special reference to antipsoriatic mechanisms. BrJ Dermatol, 132:675-82.

van de Kerkhof PC. 1998. In vivo effects of vitamin D3 analogues. $J$ Dermatol Treat, 9(Suppl. 3):S25-9. van de Kerkhof PC. 2004. The impact of a two-compound product containing calcipotriol and betamethasone dipropionate (Daivobet ${ }^{\circledR} /$ Dovobet $^{\mathbb{R}}$ ) on the quality of life in patients with psoriasis vulgaris: a randomized controlled trial. Br J Dermatol, 151:663-8.

Van Rossum MM, van Erp PEJ, van de Kerkhopf PC. 2001. Treatment of psoriasis with a new combination of calcipotriol and betamethasone dipropionate: a flow cytometric study. Dermatology, 203:148-52.

Vissers WH, Berends M, Muys L, et al. 2004. The effect of the combination of calcipotriol and betamethasone dipropionate versus both monotherapies on epidermal proliferation, keratinization and T-cell subset in chronic plaque psoriasis. Exp Dermatol, 13:106-12.

White S, Vender R, Thaçi D, et al. 2006. Use of calcipotriene cream (Daivonex ${ }^{\circledR} /$ Dovonex $^{\circledR}$ cream) following acute treatment of psoriasis vulgaris with the alcipotriene/betamethasone dipropionate two-compound product (Daivobet ${ }^{\mathbb{B}} /$ Dovobet $^{\mathbb{R}}$ ): a randomized, parallel-group clinical trial. Am J Clin Dermatol, 7:177-84.

Wissink S, van Heerde EC, van Der BB, et al. 1998. A dual mechanism mediates repression of NF-KAPPAB activity by glucocorticoids. Mol Endocrinol, 12:255-363. 